\title{
Genomic insights into natural selection in the common loon (Gavia immer): evidence for aquatic adaptation
}

\author{
Zach G. Gayk ${ }^{1,2^{*}}$ D, Diana Le Duc ${ }^{3,4}$, Jeffrey Horn ${ }^{5}$ and Alec R. Lindsay ${ }^{1}$
}

\begin{abstract}
Background: The common loon (Gavia immer) is one of five species that comprise the avian order Gaviiformes. Loons are specialized divers, reaching depths up to $60 \mathrm{~m}$ while staying submerged for intervals up to three minutes. In this study we used comparative genomics to investigate the genetic basis of the common loon adaptations to its ecological niche. We used Illumina short read DNA sequence data from a female bird to produce a draft assembly of the common loon (Gavia immer) genome.

Results: We identified 14,169 common loon genes, which based on well-resolved avian genomes, represent approximately 80.7\% of common loon genes. Evolutionary analyses between common loon and Adelie penguin (Pygoscelis adeliae), red-throated loon (Gavia stellata), chicken (Gallus gallus), northern fulmar (Fulmarus glacialis), and rock pigeon (Columba livia) show 164 positively selected genes in common and red-throated loons. These genes were enriched for a number of protein classes, including those involved in muscle tissue development, immunoglobulin function, hemoglobin iron binding, G-protein coupled receptors, and ATP metabolism.

Conclusions: Signatures of positive selection in these areas suggest the genus Gavia may have adapted for underwater diving by modulating their oxidative and metabolic pathways. While more research is required, these adaptations likely result in (1) compensations in oxygen respiration and energetic metabolism, (2) low-light visual acuity, and (3) elevated solute exchange. This work represents the first effort to understand the genomic adaptations of the common loon as well as other Gavia and may have implications for subsequent studies that target particular genes for loon population genetic, ecological or conservation studies.
\end{abstract}

Keywords: Comparative genomics, Freshwater adaptation, Diving, Positive selection, Migration

\section{Background}

Loons, order Gaviiformes, are a small extant group of five species, all of which are specialized for diving in freshwater and marine-coastal aquatic habitats. They exhibit a number of specialized morphological traits used for diving and piscivory, including posteriorly-positioned feet for foot-propelled diving, dense bones [1], and compressible feathers to reduce buoyancy forces [2]. Presumably many of these specialized anatomical and physiological traits are

\footnotetext{
*Correspondence: zachgayk@gmail.com

'Biology Department, Northern Michigan University, 1401 Presque Isle Avenue, Marquette 49950, Michigan, USA

${ }^{2}$ Biology Department, University of Windsor, 401 Sunset Avenue, Windsor N9B 3P4, Ontario, Canada

Full list of author information is available at the end of the article
}

influenced by genes that have been subject to natural selection in loons and their ancestors.

Work from penguins [3] suggested that these ocean diving birds have been subject to positive selection in adipocyte, feather keratin, wing development, and opsin genes. In exclusively saltwater penguins (Sphenisciformes), genes controlling the shape of the eye lens were under selection to maximize sight below water [3]. In penguins, evidence for expansions of gene families related to lipid and betakeratin production was found associated with polar saltwater aquatic foraging [3], but no prior work has focused purely on adaptations for freshwater aquatic diving. However, adaptation to freshwater aquatic habitats such as those occupied by loons during nesting, likely presents different selection pressures to saltwater aquatic divers such as penguins. First, freshwater habitats cut off from ocean currents 
freeze during winter, requiring long-distance migration biannually. Because optimal aerodynamics required for migration is at odds with the optimal morphology for diving, selection must balance both aquatic and flight morphologies in loons, unlike in flightless penguins where selection pressures are optimized for diving and terrestrial locomotion. This could result in selection on development genes as well as for increased lipid metabolism during migration.

Although loons are volant, they are unable to walk on land and are thus less terrestrial than flightless penguins [4]; loons only set foot to land to copulate and incubate eggs [4]. Loons are also required to osmoregulate in more varied conditions than most other aquatic birds, as loons spend roughly half of each year in saltwater habitats (non-breeding season) [5] and half of each year on freshwater habitats (breeding season) [4]. Comparing the origin of osmoregulatory adaptations in a phylogenetic framework is particularly worthwhile because of the recent advances in avian genomics which now allow for comparisons of species from nearly every avian order, including species of waterbirds that are either saltwater or freshwater specialists [6].

We sequenced and assembled a draft genome of Gavia immer, the common loon, to improve our understanding of how genomic features evolve during adaptation to aquatic habitats and diving. We performed comparative genomics analyses using red-throated loon genes along with common loon genes to increase the power to detect Gavia-specific positive selection, in relation to Adelie penguin, (Pygoscelis adeliae), chicken (Gallus gallus), northern fulmar (Fulmarus glacialis), and rock pigeon (Columba livia) genomes [7]. We identified genomic changes in the common loon that modulate their oxidative and energetic metabolism, which may support their diving behaviour.

\section{Results}

\section{Genome assembly}

The Illumina 2000 runs used $8 \mathrm{~kb}$ inserts to generate $100 \mathrm{bp}$ paired-end reads. We only used reads that passed quality control filtering with scores between Q20 and Q30 (99.26\% and $95.43 \%$ confidence in correct base call respectively). This reduced the initial number of 499,620,770 reads with $50,461,697,770$ individual bases by $58.26 \%$, leaving $291,098,878$ usable reads totaling $26,946,081,239$ individual bases post filtering.

ABySS assemblies of the common loon genome with eight different $k$-mer sizes ranging from $k 25-k 64$ yielded contig N50 values from 641 to $814 \mathrm{bp}$ in length. The $k$-mer size that optimized contig N50 was $k=30$ with an N50 of $814 \mathrm{bp}$. The $k=30$ assembly was therefore selected as the best assembly to submit to evolutionary analyses. Based on BBMAP analyses, the $k=30$ assembly consisted of 5,237,924 contigs with a total contig length of 767,326,331 bp. For the $k=30$ assembly, $k$-mer coverage per ploidy of the diplod sequenced genome was estimated to be approximately 11 . $84 \times$. Despite the fragmented nature of the genome assembly, 62,409 contigs had lengths of 1 kilobases $(\mathrm{kb})$ or greater. While this comprised only $1.2 \%$ of the total contigs and $12.8 \%$ of total assembly length, such sequences were of sufficient length for analyses of entire genes and smaller sequences were still suitable for analyses of whole or partial exons.

From calculations using BBMAP, percent GC content of the $k=30$ assembly was estimated to be approximately 45 . $7 \%$, while the proportion comprised of AT content was approximately $54 \%$. Genomic GC content was highly heterogeneous across the genome assembly at a sliding widow size of $10 \mathrm{~kb}$. Local variation in GC content ranged from approximately $30 \%$ to $70 \%$ (Fig. 1). GC content was especially low within the region spanning $2 \mathrm{Mbp}$ of the genome assembly (Fig. 1), which most likely represents a difficult to assemble repetitive region of the common loon genome.

\section{Gene identification}

From tabular BLAST output with $k=30$ assembly scaffolds as query and chicken coding sequence as subject,

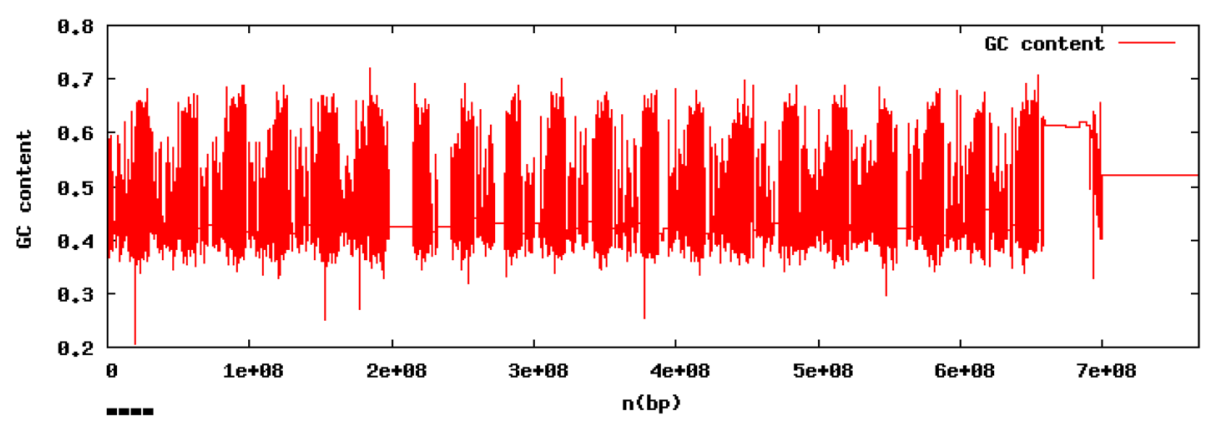

Fig. 1 Percent GC content of the common loon $k=30$ genome assembly. Variation in the percentage of bases composed of paired G (guanine) and C (cytosine) is shown across assembled bases from 1 to 767,326,331 base pairs in the total assembly length. Individual values of GC across the genome assembly were plotted using a sliding window analysis set to examine every $10 \mathrm{Kbp}$. Regions with no GC content, shown as white spaces, likely represent sequencing gaps 
a database of 136,755 matches to Ensembl transcripts [7] was returned. Ensembl transcripts had between two to eight result matches to the same scaffold in the $k=30$ assembly. After filtering with BiomaRt [8], the list of genes identified in the $k=30$ common loon assembly consisted of 13,821 known chicken genes in Ensembl release 81 and a further 348 unidentified transcripts with unknown function, for a total of 14,169 common loon genes (Additional file 1). These results indicate that $80.7 \%$ of chicken genes in Ensembl release 81 were identified within the common loon assembly (Additional file 2).

\section{Evolutionary analyses}

Out of 14,169 common loon genes, a total of 9665 protein coding sequences were able to be frame-corrected and used in PAML analyses with a high degree of confidence (Additional files 1 and 3). The remaining 4504 fragments had no open reading frame despite aligning to known genes in the five other species.

After removal of sequences with no synonymous mutations, which can lead to spurious $\mathrm{dN} / \mathrm{dS}$ calculation [9], 700 out of 9665 gene sequences $(7.2 \%)$ had dN/dS greater than one. Likelihood ratio tests resulted in a significant improvement of likelihood scores under the model of positive selection for 164 of 700 genes (23.4\%). This set of
164 genes therefore had statistical support for positive selection in common loon and red-throated loons, relative to four other background genomes (Fig. 2) and were considered the final set of positively selected genes. In this gene-set, 41 Gavia genes with the highest LRT values had functions in solute exchange and ATP metabolism (Tables 1 and 2). A Candidate gene GNB1 potentially involved in low-light signal transduction was also identified as positively selected, as was $H M O X 1$, which may have a role in oxygen respiration under conditions of diveinduced local hypoxia.

\section{Discussion}

\section{Assembly quality}

The highly fragmented state of the current $k=30$ genome assembly, judged by both number of contigs and contig $\mathrm{N} 50$, is less than that of highly vetted genomes such as chicken, and zebra finch (Taeniopygia guttata) [10]. Recently published genome assemblies from birds including the Hume's ground tit (Pseudopodoces humilis) [11], golden eagle (Aquila chrysaetos) [12], and Adelie penguin [13] all have contig N50 values in the range of 19-164 Kbp, whereas the current common loon assembly has a contig N50 of 814 bp. Assembly quality most closely approximates that of the black grouse (Tetrao tetrix) draft

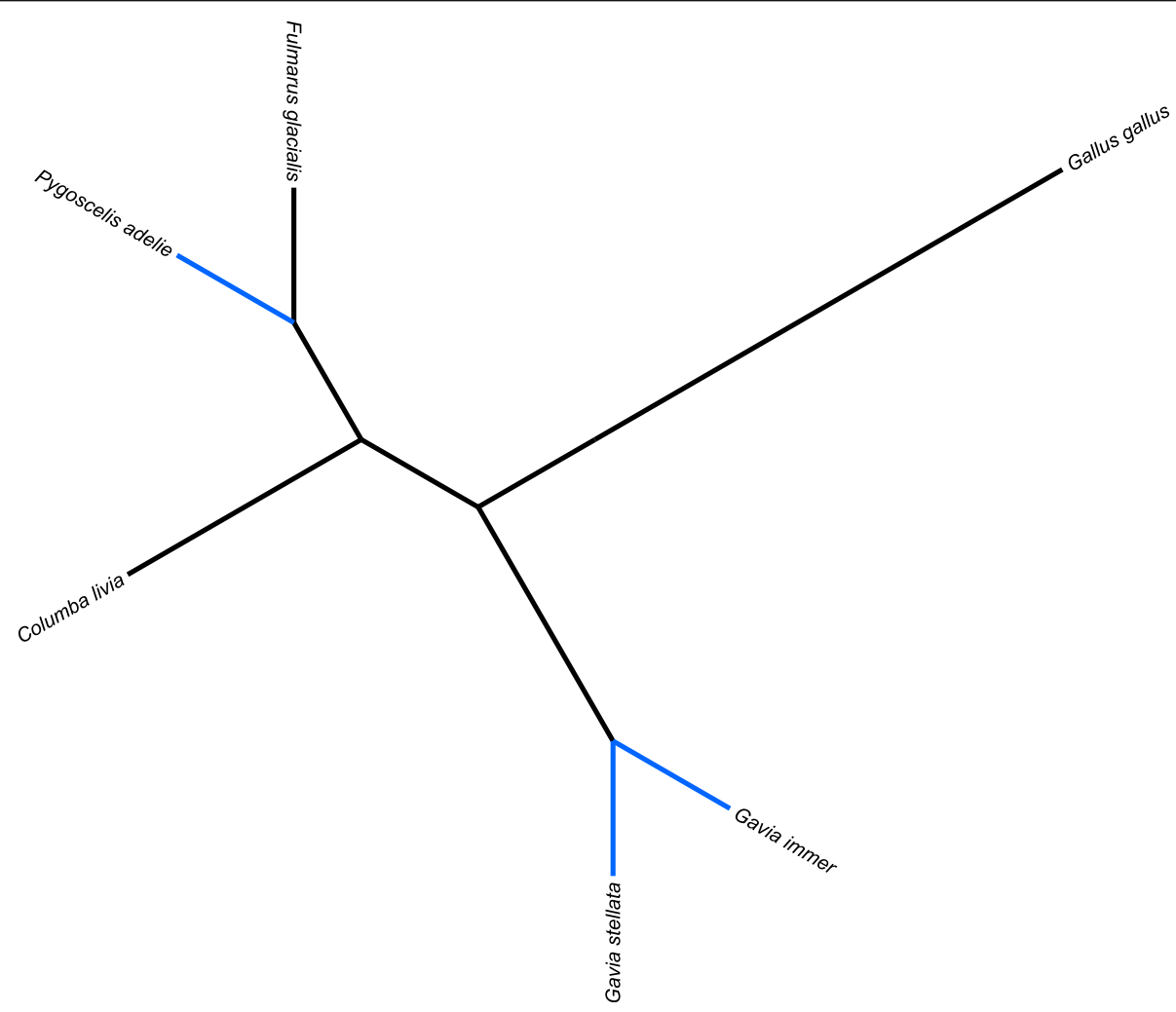

Fig. 2 Cladogram representation of common loon (Gavia immer), red-throated-loon (Gavia stellata), northern fulmar (Fulmarus glacialis), Adelie penguin (Pygoscelis adelie), rock pigeon, (Columba livia), and chicken (Gallus gallus). The aquatic diving lineages are highlighted in blue 
Table 1 Common (Gavia immer) and Red-throated loon (Gavia stellata) genes with the highest statistical support indicating either positive selection or purifying selection, indicated by faster or slower evolution under COL_Gst_trend, respectively. Common loon is abbreviated COL and Red-throated loon is abbreviated Gst

\begin{tabular}{|c|c|c|c|c|c|c|c|c|}
\hline GenelD & seq_length & Inl__model 0 & $\omega$ model 0 & Inl_model 2 & $\omega$ background & COL_Gst & LRT & COL_Gst_trend \\
\hline EPN3 & 327 & -1152.7014 & 0.01707 & $-1104,593$ & 0.01782 & 0.01984 & 96.217 & faster \\
\hline ZBTB5 & 249 & -672.25763 & 0.20841 & $-661,74,052$ & 0.08824 & 1258 & 21,034 & faster \\
\hline ASB13 & 159 & -433.96493 & 0.2276 & -423.50404 & 0.03184 & 0.93344 & 20.922 & faster \\
\hline$|L 4| 1$ & 771 & $-2150,5564$ & 0.11603 & $-2142,9682$ & 0.09269 & $0,45,843$ & 15.176 & faster \\
\hline ZSWIM8 & 342 & $-438,89,839$ & 0.05848 & $-431,37,865$ & 0.01099 & 2.00206 & 15.04 & faster \\
\hline TUBB3 & 228 & -670.71185 & 0.00912 & $-665,15,958$ & 0.01716 & 0.00017 & 11.105 & slower \\
\hline 315,773 & 228 & -821.91841 & 0.01812 & -816.56462 & 0.02302 & 0.00154 & 10.708 & slower \\
\hline FBX02 & 252 & -702.0616 & 0.51324 & -696.7442 & $0,62,797$ & 0,0001 & 10.635 & slower \\
\hline SYT11 & 354 & -831.44038 & 0.0465 & -826.3884 & 0.03646 & $1,27,058$ & 10.104 & faster \\
\hline cKir2.3 & 906 & -1761.5536 & 0.02201 & -1756.6812 & 0.00922 & 0.11328 & 9.7449 & faster \\
\hline SEMA5A & 258 & -624.89875 & 0.28427 & -620.04765 & 0.16011 & 0.91611 & 9.7022 & faster \\
\hline PNPLA6 & 210 & -651.71811 & 0.01012 & -646.99188 & 0.00121 & 0.03078 & 9.4525 & faster \\
\hline CENPJ & 399 & -985.68333 & 0.52198 & -980.97548 & 0.71507 & 0.11002 & 9.4157 & slower \\
\hline POLR3A & 219 & -452.46578 & 0.03422 & -447.92294 & 0.0001 & 0.1951 & 9.0857 & faster \\
\hline TBC1D8 & 204 & -648.48472 & 0.0926 & -640.07889 & 0.0001 & 3.96808 & 16.812 & faster \\
\hline C5RNP3 & 234 & $-755,24,789$ & 0.05295 & -748.12504 & 0.0001 & 0.69521 & 14.246 & faster \\
\hline PHAX & 246 & $-550,29,897$ & 0.10575 & $-543,21,977$ & 0.0197 & 0.32286 & 14.158 & faster \\
\hline PCD H17 & 267 & -501.13075 & 0.0589 & -494.61423 & 0.0001 & 0.28444 & 13.033 & faster \\
\hline NT5C1A & 234 & $-446,31,726$ & 0.01154 & $-441,0027$ & 0.0001 & 0,2497 & 10,629 & faster \\
\hline PITX2 & 354 & -1137.3695 & 0.03826 & $-1132,3063$ & 0,01375 & 0.79758 & 10.126 & faster \\
\hline LGR5 & 354 & -662.90136 & 0.07076 & $-658,29,332$ & 0.02553 & 0.54755 & 9.2161 & faster \\
\hline MON1A & 705 & -1313.0707 & 0.00959 & -1308.521 & 0.00345 & 0.05225 & 9.0994 & faster \\
\hline KCNJ5 & 615 & -1150.454 & 0.02875 & $-1145,9671$ & 0,01487 & 0.34767 & 8,9738 & faster \\
\hline $\mathrm{CDH} 7$ & 234 & -465.08493 & 0.12236 & -460.98436 & 0.0509 & 1.84634 & 8.2011 & faster \\
\hline SCN2A & 708 & -1625.9186 & 0.06846 & -1621.8739 & 0.04567 & 0.17324 & 8.0892 & faster \\
\hline
\end{tabular}

assembly [14], which had a contig N50 value of $1238 \mathrm{bp}$. Despite the fragmented nature of the current common loon assembly, contig lengths as indicated by N50 appear to be adequate for identifying protein coding regions of genes [15]. However, lacking long contiguous scaffolds, the exact placement and order of particular contigs can not be determined and thus is likely inadequate for analyses of synteny [16].

Conclusions about assembly quality must be put in the proper perspective about the resolution desired in analyses. For opportunistic analyses of selection between closely related species making use of available contigs, this assembly has value. The fragmented nature of the best ABySS assembly can be attributed to several factors including: (1) large (8 kb) insert libraries of only one size used in assembly, (2) a short read size of $100 \mathrm{bp}$, and (3) low sequencing depth. $K$-mer coverage per ploidy of the diploid loon genome was calculated to be $11.83 \times$, whereas target $k$-mer coverage should be in the range of $20-30 \times$ for a high-quality genome assembly (B. Bushnell pers. comm.). In this assembly, the odds of correctly assembling each read per ploidy are low given that actual coverage per ploidy is between one-half to one-third the target range for a good genome assembly (B. Bushnell pers. comm.) [17].

\section{Genome size and GC content}

Avian genomes are between one-third to one-half the size of mammalian genomes. This may occur because flight imposes metabolic constraints limiting cell size and increasing the efficiency of cellular metabolism with a higher cell surface area [18]. Estimates from well studied bird genomes suggest typical avian genomes should be in the range of $1-1.5 \mathrm{Gbp}$ with a maximum number of genes under 20,000 [12]. The total consecutive sequence length of the common loon genome assembly was 767 $\mathrm{Mpb}$. Although assembly quality makes estimation of the actual common loon genome size impossible, this figure could indicate we have assembled between 50 and $76 \%$ of 
Table 2 Significantly evolving genes shared or with similar gene functions between aquatic Common and Red-throated loons (Gavia lineage) and Adelie Penguin (Pygoscelis adelie). Gene omega values of 999 indicate a lack of nonsynonymous mutations, but are retained where the other lineage contains nonsynonymous mutations

\begin{tabular}{|c|c|c|c|c|c|c|c|}
\hline GENE & Branch & Function & seq_length & $\omega$ model 0 & $\omega$ COL_Gst & LRT & $\begin{array}{l}\text { COL Gst } \\
\text { trend }\end{array}$ \\
\hline ATAD2B & Gavia & ATPase family, AAA domain containing $2 \mathrm{~B}$ & 213 & 0.13786 & 0.53611 & 5.06462 & faster \\
\hline BMP6 & P. adelaie & bone morphogenetic protein 6 & 75 & 0.01916 & 999 & 4.69446 & faster \\
\hline BAMBI & Gavia & BMP and activin membrane-bound inhibitor homolog & 156 & 0.10285 & 0.41534 & 6.69316 & faster \\
\hline CALHM3 & P. adelaie & calcium homeostasis modulator 3 & 246 & 0.2885 & 2.52871 & 7.65325 & faster \\
\hline CIB1 & Gavia & calcium and integrin binding 1 & 93 & 0.02077 & 17.66026 & 4.15427 & faster \\
\hline CDHR1 & P. adelaie & cadherin related family member 1 & 228 & 0.06232 & 0.24732 & 7.04434 & faster \\
\hline $\mathrm{CDH} 7$ & Gavia & cadherin 7 , type 2 & 234 & 0.12236 & 1.84634 & 8.20113 & faster \\
\hline CHEK2 & $\begin{array}{l}\text { P. adelaie/ } \\
\text { Gavia }\end{array}$ & checkpoint kinase 2 & 246 & 0.06661 & 0.64046 & 5.29991 & faster \\
\hline DDX11 & P. adelaie & DEAD/H (Asp-Glu-Ala-Asp/His) box helicase 11 & 114 & 0.29558 & 1.1461 & 5.05993 & faster \\
\hline DDX55 & Gavia & DEAD (Asp-Glu-Ala-Asp) box polypeptide 55 & 168 & 0.19828 & 999 & 8.64589 & faster \\
\hline MAT1A & $\begin{array}{l}\text { P. adelaie/ } \\
\text { Gavia }\end{array}$ & methionine adenosyltransferase I, alpha & 51 & 0.08453 & 1.8137 & 6.53492 & faster \\
\hline MRPL41 & P. adelaie & mitochondrial ribosomal protein $L 41$ & 93 & 0.05377 & 999 & 5.09515 & faster \\
\hline MRPS30 & Gavia & mitochondrial ribosomal protein S30 & 105 & 0.07025 & 0.26428 & 5.5027 & faster \\
\hline RNF144B & P. adelaie & ring finger protein 144B & 201 & 0.41768 & 999 & 7.94759 & faster \\
\hline RNF151 & P. adelaie & ring finger protein 151 & 129 & 0.01272 & 0.10092 & 3.84739 & faster \\
\hline RNF122 & Gavia & ring finger protein 122 & 111 & 3.11562 & 4.51569 & 4.85065 & slower \\
\hline RNF14 & Gavia & ring finger protein 14 & 171 & 0.21056 & 0.0001 & 4.13336 & slower \\
\hline RNF150 & Gavia & ring finger protein 150 & 111 & 0.07654 & 0.17727 & 5.04599 & faster \\
\hline SLC15A4 & P. adelaie & solute carrier family 15 (oligopeptide transporter), member 4 & 165 & 0.06417 & 999 & 5.59949 & faster \\
\hline SLC22A4 & P. adelaie & solute carrier family 22 (organic cation transporter), member 4 & 213 & 0.09995 & 999 & 3.88664 & faster \\
\hline SLC30A8 & P. adelaie & solute carrier family 30 (zinc transporter), member 8 & 144 & 0.04012 & 999 & 4.49118 & faster \\
\hline SLC20A1 & Gavia & solute carrier family 20 (phosphate transporter), member 1 & 63 & 0.02234 & 0.43825 & 6.31834 & faster \\
\hline SLC32A1 & Gavia & solute carrier family 32 (GABA vesicular transporter), member 1 & 963 & 0.00303 & 0.04424 & 5.14974 & faster \\
\hline SLC4A8 & Gavia & $\begin{array}{l}\text { solute carrier family 4, sodium bicarbonate cotransporter, } \\
\text { member } 8\end{array}$ & 126 & 0.02901 & 0.12003 & 7.24001 & faster \\
\hline SLC5A12 & Gavia & $\begin{array}{l}\text { solute carrier family } 5 \text { (sodium/monocarboxylate } \\
\text { cotransporter), member } 12\end{array}$ & 138 & 0.4122 & 0.0001 & 5.3412 & slower \\
\hline TBC1D24 & P. adelaie & TBC1 domain family member 24 & 306 & 0.05272 & 1.25765 & 10.2849 & faster \\
\hline TBC1D8 & Gavia & TBC1 domain family, member 8 (with GRAM domain) & 204 & 0.0926 & 3.96808 & 16.8117 & faster \\
\hline WDR31 & $\begin{array}{l}\text { P. adelaie/ } \\
\text { Gavia }\end{array}$ & WD repeat domain 31 & 162 & 0.20233 & 0.0001 & 4.99304 & slower \\
\hline
\end{tabular}

the common loon total genomic content using published genome sizes [12] as a reference.

\section{Evolutionary analyses and biological significance of genes under positive selection}

Patterns of gene enrichment suggest that selection since the common loon-chicken split approximately 90 mya [6] has acted on candidate genes related to hemoglobin affinity for oxygen, solute exchange, immunoglobulin function related to immune defense, nervous system development and a number of molecular pathways related to DNA metabolic function, and G-receptor pathways potentially involved in low-light visual acuity.

A selection analysis of emperor (Aptenodytes forsteri) and Adelie penguin (Pygoscelis adeliae) genomes identified a number of positively selected genes related to Antarctic diving and cold tolerance, and vision in low-light environments [3]. They found: a greater number of $\beta$-keratin genes-which comprise $90 \%$ of mature feather barbs and barbules - than in any other bird species, a reduction in the number of opsin genes to three trichromatic classes as opposed to four found in most birds as an adaptation to low light environments, positive selection in FASN which 
encodes lipid metabolism and lipogenesis, and mutation of 17 genes associated with short limb and truncated dorsal morphology for flipper-based diving.

Li et al.'s [3] focus on identifying genes associated purely with penguin flightlessness and polar marine physiology provide the most phylogenetically similar but still somewhat restricted comparison to loons from an ecological point of view. Although loons (Gaviiformes) and penguins (Sphenisciformes) both may have originated in the Southern Hemisphere [19] (the exact origin is unresolved), loons have since evolved to breed and forage on freshwater ponds and lakes during summer and to reside and forage in marine environments during winter. Different buoyancy forces and osmotic exchange rates exist in freshwater and saltwater environments and loons are one of few migratory aquatic bird classes that exploit both during the same year, and potentially the same day. Aptenodytes penguins dive much deeper than loons, reaching depths over $300 \mathrm{~m}$, so selection pressures on visual systems might be different in penguins which experience lower light conditions than shallower diving loons [20]. No loon species have polar distributions and while they do inhabit cold arctic and boreal regions, migration limits the need for the specialized feather and adipose tissue of penguins. It is likely that genes for solute exchange and osmoregulation are the most important class of positively selected genes in the Gavia lineage when compared across five other avian genomes. SLC48A, and SLC2OA1 in particular may have a role in maintaining ion and $\mathrm{pH}$ balance and are therefore candidate genes in the Gavia lineage for maintaining ion homeostasis.

In common loons, the high aerobic and metabolic costs of a physiology adapted foremost to deep-water diving, but also long distance (trans-continental) aerial migration indicate disparate selection pressures have shaped loon evolution. The optimal morphology for diving, (i.e. high mass, easily concealed wings, ventrally positioned feet) presents severe trade-offs for flight, as high mass and narrow wings make it difficult for loons to become airborne and require high flight speeds once aloft [4]. We hypothesize that a number of genes associated with ATP and metabolism may have been positively selected in common loons to maximize energy production in these environments.

\section{Conclusions}

Most of the hypotheses for positive selection in loons remain speculative unless confirmed through additional studies. However, now that candidate positively selected genes are available, future work could examine the expression of these genes through RNA-sequencing [21]; in particular the mechanisms through which osmoregulation is balanced in salt and freshwater environments, low-light phototransduction is achieved, and oxygen saturation is maximized in flight and diving should be elucidated. The most compelling approach to interpret the adaptive context of common loon evolution would integrate high-throughput genomic data (as in this study), and established common loon natural history, with direct hypothesis driven tests. This work provides a reference set of common loon genes that can now serve as targets for more detailed follow-up work. In addition, this study demonstrates that high throughput genome assembly methods can be used inexpensively to identify coding regions of genes. As next generation sequencing (NGS) continues to become more common and whole or partial genomic data become available for large numbers of species, more studies may develop tools to harvest incomplete genome assemblies for evolutionary comparative analyses.

\section{Methods \\ De novo assembly}

We used Illumina short read $2 \times 100$ base pair data generated by Axeq Technologies Inc. from a single female common loon for a de novo assembly of the common loon genome. The final sequencing output resulted in 499,620,770 sequence reads, comprising 50,461,697,770 total bases in all summed reads. We assembled the genome using the raw short read sequence read data with ABySS [22], which performs particularly well with complex vertebrate genomes [23].

We used the message passing interface (MPI) version of ABySS 1.5.2 [22] on a Rocks compute cluster to assemble eight versions of the common loon genome, each with different $k$-mer values. The highest quality genome assembly, judged by contig N50, was then annotated in an effort to maximize the length of protein coding regions for evolutionary analyses [17]. For the best assembly, we evaluated genome assembly completeness of entire proteins coding regions with the Core Eukaryotic Genome Mapping Approach (CEGMA) [12].

\section{Reference-guided assembly}

To further improve contig lengths, we aligned each scaffold in our assembly to the publically available redthroated loon (Gavia stellata) genome [13]. To align scaffolds in the ABySS assembly to the red-throated loon genome we used the Burrows Wheeler Aligner (BWA) package [24]. After mapping the ABySS contigs to the red-throated loon genome, we again assessed the N50 of reference-mapped contigs and scaffolds and if they had not improved in length compared to the de novo assembly we extracted the paired-end Next generation sequencing (NGS) sequence read files and aligned the raw sequence reads to the red-throated loon genome [14]. We then merged consensus sequences from the ABySS 
[22] assembly alignment with the NGS read alignment using the program SAMTools [25]. This resulted in extension of scaffolds suitable for Gene Identification and analysis [14]. We used BBMAP [26] to extract assembly statistics and convert the assembly into fasta format.

\section{Gene identification}

We used local BLASTn [27] to search the resulting common loon genome assembly, scaffold by scaffold, against the Adelie penguin, red-throated loon, chicken northern fulmar and rock pigeon [13] coding sequences (Ensembl release 81) [7]. We generated BLASTn [27] results using a custom-formatted script for 12-column tabular output. Gene names were then retrieved for each hit in the BLAST tabular output by using the Ensembl BiomaRt web interface [8]. To check whether we retrieve the same genomic region, chicken genes were subsequently mapped back to common loon scaffolds using a custom Python script.

\section{Evolutionary analyses}

We used the resulting gene set to identify genes within the common loon assembly where evolutionary changes occurred since divergence from Adelie penguin, chicken, northern fulmar, and rock pigeon [6, 7]. To increase the power to detect Gavia-specific positive selection, we used red-throated loon (Gavia stellata) genes along with common loon genes identified in this study as the foreground branch.

As Illumina sequencing is not selective as to which DNA strand is amplified [28], 50\% of the gene fragments in the loon assembly were on non-coding rather than coding strands. All common loon gene fragments analyzed for evidence of selection were first converted to coding strands and then placed into an open reading frame using custom Python scripts (Additional file 2). Because some identified gene sequences were fragments too short for biologically meaningful analysis of codons in PAML analyses [29], only fragments with the longest uninterrupted run of at least 200 aligned bases in each multiple sequence alignment were kept. We scanned for differently evolving genes with the CODEML program under a branch model (model $=2$, two $\omega$ s for foreground and background branches, respectively, vs. $\operatorname{model}=0$, one $\omega$ for all branches, compared via likelihood ratio test), [30]. We computed Likelihood Ratio tests (LRT) for each $\omega$ ratio under a null assumption of purely neutral evolution. The resulting likelihood scores were used to calculate an LRT statistic, $-2\left(\operatorname{lnL}_{\text {null }}-\ln \mathrm{L}_{\text {estimated }}\right)$, which was then compared to a chi-square distribution with one degree of freedom and $\alpha=0.05$.

\section{Additional files}

Additional file 1: Total Genes. (XLSX $5169 \mathrm{~kb}$ )

Additional file 2: Methods and Overview. Description of Computer Resources. Locations of Genomic Assembly Data and Scripts. (DOCX 1266 kb)

Additional file 3: Significantly_Evolving_Genes. (XLSX 92 kb)

\section{Acknowledgements}

We thank Dr. Kate Teeter and Dr. Kurt Galbreath for assistance with bioinformatic and phylogenetic analyses. Thanks also to computer science students Nolan Earl and Justin Syria for scripting and coding assistance. We thank Torsten Schöneberg for valuable input on evolutionary analyses.

Funding

This work was funded by an NMU Faculty Grant to ARL.

\section{Availability of data and materials}

Data resulting from this project are included as supplementary materials. Additional scripts are available on request from the corresponding author.

\section{Authors' contributions}

ARL conceived the project. ZG, ARL and JH assembled the fragmented common loon genome. DL and ZG conducted genome alignments and analyses of positive selection. ZG wrote the manuscript draft. All authors edited and approved of the final manuscript. This paper follows the FLAE convention for authorship.

\section{Competing interests}

The authors declare they have no competing interests.

\section{Publisher's Note}

Springer Nature remains neutral with regard to jurisdictional claims in published maps and institutional affiliations.

\section{Author details \\ ${ }^{1}$ Biology Department, Northern Michigan University, 1401 Presque Isle Avenue, Marquette 49950, Michigan, USA. ${ }^{2}$ Biology Department, University of Windsor, 401 Sunset Avenue, Windsor N9B 3P4, Ontario, Canada. ${ }^{3}$ Institute of Human Genetics, University of Leipzig Hospitals and Clinics, Leipzig, Germany. ${ }^{4}$ Department of Evolutionary Genetics, Max Planck Institute for Evolutionary Anthropology, Leipzig, Germany. ${ }^{5}$ Department of Mathematics and Computer Science, Northern Michigan University, 1401 Presque Isle Avenue, Marquette 49950, Michigan, USA.}

Received: 1 November 2017 Accepted: 16 April 2018

Published online: 27 April 2018

\section{References}

1. Chatterjee S. The morphology and systematics of. Proceedings of the 5th symposium of the Society of Avian Paleontology and Evolution; 2002. p. 125-55.

2. Schorger AW. The deep diving of the loon and old-squaw and its mechanism. The Wilson Bulletin. 1947:59:151-9.

3. Li C, Zhang Y, Li J, Kong L, Hu H, Pan H, et al. Two Antarctic penguin genomes reveal insights into their evolutionary history and molecular changes related to the Antarctic environment. GigaScience. 2014;3:1-15.

4. Evers DC, Paruk JD, McIntyre JW, Barr JF. In: Poole AF, editor. Common loon (Gavia immer). The Birds of North America. Ithaca, NY: Cornell Lab of Ornithology; 2010.

5. Kenow KP, Meyer M, Evers DC, Douglass DC, Hines J. Use of satellite telemetry to identify common loon migration routes. Staging Areas and Wintering Range Waterbirds. 2018:25:449-58.

6. Zhang G, Li C, Li Q, Li B, Larkin DM, Lee C, et al. Comparative genomics reveals insights into avian genome evolution and adaptation. Science. 2014; 346:1311-20.

7. Hubbard T, Barker D, Birney E, Cameron G. The Ensembl genome database project. Nucleic Acids Res. 2002;1:38-41.

8. Smedley D, Haider S, Ballester B, Holland R, London D, Thorisson G, et al. BioMart - biological queries made easy. BMC Genomics. 2009;10:22. 
9. Angelis K, Reis Dos M, Yang Z. Bayesian estimation of nonsynonymous/ synonymous rate ratios for pairwise sequence comparisons. Mol Biol Evol. 2014:31:1902-13.

10. International Chicken Genome Sequencing Consortium. Sequence and comparative analysis of the chicken genome provide unique perspectives on vertebrate evolution. Nature. 2004:432:695-716.

11. Cai Q, Qian X, Lang Y, Luo Y, Pan S, Hui Y, et al. The genome sequence of the ground tit Pseudopodoces humilis provides insights into its adaptation to high altitude. Genome Biol. 2013;14:R29.

12. Doyle JM, Katzner TE, Bloom PH, Ji Y, Wijayawardena BK, DeWoody JA. The genome sequence of a widespread apex predator, the golden eagle (Aquila chrysaetos). PLoS One. 2014;9:e95599.

13. Zhang G, Li B, Li C, Gilbert MTP, Jarvis ED, Wang J. Comparative genomic data of the Avian Phylogenomics Project. Gigascience. 2014;3:1-8.

14. Wang B, Ekblom R, Bunikis I, Siitari H. Glund JH. Whole genome sequencing of the black grouse (Tetrao tetrix): reference guided assembly suggests faster-Z and MHC evolution. BMC genomics. BMC Genomics. 2014;15:1-13.

15. Parra G, Bradnam K, Ning Z, Keane T, Korf I. Assessing the gene space in draft genomes. Nucleic Acids Res. 2009;37:289-97.

16. Oleksyk TK, Pombert J-F, Siu D, Mazo-Vargas A, Ramos B, Guiblet W, et al. A locally funded Puerto Rican parrot (Amazona vittata) genome sequencing project increases avian data and advances young researcher education. Gigascience. 2012;1:14

17. Yandell M, Ence D. A beginner's guide to eukaryotic genome annotation. Nat Rev Genet. 2012;13:329-42.

18. Nam K, Mugal C, Nabholz B, Schielzeth H, Wolf JBW, Backström N, et al. Molecular evolution of genes in avian genomes. Genome Biol. 2010;11:R68.

19. Olson SL. Neogaeornis wetzeli Lambrecht, a cretaceous loon from Chile (Aves: Gaviidae). Journal of vertebrate paleontology. Taylor \& Francis. Ltd. 1992;12:122-4.

20. Pütz K, Cherel Y. The diving behaviour of brooding king penguins (Aptenodytes patagonicus) from the Falkland Islands: variation in dive profiles and synchronous underwater swimming provide new insights into their foraging strategies. Mar Biol. 2005;147:281-90.

21. Alvarez M, Schrey AW, Richards CL. Ten years of transcriptomics in wild populations: what have we learned about their ecology and evolution? Mol Ecol. 2015;24:710-25.

22. Simpson JT, Wong K, Jackman SD, Schein JE, Jones SJM, Birol I. ABySS: a parallel assembler for short read sequence data. Genome Res. 2009:19:1117-23.

23. Zhang W, Chen J, Yang Y, Tang Y, Shang J, Shen B. A practical comparison of de novo genome assembly software tools for next-generation sequencing technologies. PLoS One. 2011;6:e17915.

24. Li H, Durbin R. Fast and accurate long-read alignment with burrowswheeler transform. Bioinformatics. 2010;26:589-95.

25. Li H, Handsaker B, Wysoker A, Fennell T, Ruan J, Homer N, et al. The sequence alignment/map format and SAMtools. 2009.

26. Bushnell B. http://sourceforgenet/projects/bbmap. Accessed 20 Aug 2015.

27. McGinnis S, Madden TL. BLAST: at the core of a powerful and diverse set of sequence analysis tools. Nucleic Acids Res. 2004;32:W20-5.

28. Van Nieuwerburgh F, Thompson RC, Ledesma J, Deforce D, Gaasterland T, Ordoukhanian P, et al. Illumina mate-paired DNA sequencing-library preparation using Cre-lox recombination. Nucleic Acids Res. 2012;40:e24

29. Yang Z, Nielsen R. Estimating synonymous and nonsynonymous substitution rates under realistic evolutionary models. 2000.

30. Yang Z. PAML 4: phylogenetic analysis by maximum likelihood. Mol Biol Evol. 2007;24:1586-91.

\section{Ready to submit your research? Choose BMC and benefit from:}

- fast, convenient online submission

- thorough peer review by experienced researchers in your field

- rapid publication on acceptance

- support for research data, including large and complex data types

- gold Open Access which fosters wider collaboration and increased citations

- maximum visibility for your research: over $100 \mathrm{M}$ website views per year

At BMC, research is always in progress.

Learn more biomedcentral.com/submissions 